\title{
Unusual Verotoxin-Producing Escherichia coli Associated with Hemorrhagic Colitis
}

\author{
CHERYL A. BOPP ${ }^{1}$ KATHERINE D. GREENE, ${ }^{1}$ FRANCES POUCH DOWNES,,$^{1,2}$ EVANGELINE G. SOWERS, ${ }^{1}$ \\ JOY G. WELLS, ${ }^{1}$ AND I. KAYE WACHSMUTH ${ }^{1 *}$ \\ Enteric Bacteriology Section, Enteric Diseases Branch, Division of Bacterial Diseases, Center for Infectious Diseases, \\ Centers for Disease Control, Atlanta, Georgia 30333, ${ }^{1}$ and Department of Parasitology and Laboratory Practice, \\ School of Public Health, University of North Carolina, Chapel Hill, North Carolina 27514 ${ }^{2}$
}

Received 24 October 1986/Accepted 11 May 1987

\begin{abstract}
All strains of Escherichia coli isolated from cases of hemorrhagic colitis and sent to the Centers for Disease Control, Atlanta, Ga., over a 3-year period were assayed for toxicity in Vero cell cultures. Strains that produced moderate or high levels of verotoxin were characterized by serotype, biotype, antimicrobial resistance, plasmid profile, and adherence to HeLa cells. Over 200 isolates were typical 0157:H7 strains. Six isolates were atypical 0157:H7 strains; two were resistant to antimicrobial agents; one was indole negative, two were citrate positive, and one was urea positive. Six isolates were nonmotile 0157 strains. All of these isolates were similar to typical 0157:H7 strains by plasmid profile and negative or slow sorbitol fermentation. Eleven other verotoxigenic isolates did not possess the 0157 antigen, had a variety of plasmid profiles, and were sorbitol positive. Two of the eleven were enteropathogenic serotypes (0111:NM and 026:H11), yet none were adherent to HeLa cells. We conclude that verotoxigenic $E$. coli associated with hemorrhagic colitis includes atypical 0157 strains and other serotypes. Hence, investigators should use current screening methods with caution.
\end{abstract}

Since 1982, Escherichia coli $\mathrm{O} 157: \mathrm{H} 7$ has been recognized as the most important etiologic agent of hemorrhagic colitis, which is characterized by severe abdominal pain and watery stools, followed by frankly bloody diarrhea (14). This serotype appeared to be unique among $E$. coli and the 0157 serogroup in its association with disease and in strain characteristics, such as plasmid profile and biotype (20). Hemorrhagic colitis has also occurred as a prodrome to hemolytic uremic syndrome (HUS) (17). Outbreaks and sporadic cases of both diseases have occurred throughout the United States and Canada (7, 13, 14, 17; W. R. Gransden, S. Damm, and J. D. Anderson, Letter, Ann. Intern. Med. 103:160, 1985; W. M. Johnson, H. Lior, and G. S. Bezanson, Letter, Lancet i:76, 1983). Although $E$. coli $\mathrm{O} 157: \mathrm{H} 7$ was isolated from a frozen hamburger patty during the Michigan outbreak of hemorrhagic colitis, no natural reservoir has been well documented (20).

Although $E$. coli $\mathrm{O} 157: \mathrm{H} 7$ strains do not produce traditional $E$. coli enterotoxins and are not enteroinvasive or enteroadherent (20), they all produce at least one of a group of antigenically variant toxins that are cytopathogenic to Vero cell cultures (Johnson et al., Letter). The toxins are collectively referred to as verotoxin (VT) and individually are referred to as VT1, VT2, etc. (M. A. Karmali, M. Petric, S. Louie, and R. Cheung, Letter, Lancet i:164-165, 1986; S. M. Scotland, H. R. Smith, and B. Rowe, Letter, Lancet ii:885-886, 1985). E. coli O157:H7 toxins are also referred to by some authors as Shiga-like toxins (SLT) because SLT-I (or VT1) is neutralized by antibodies to Shigella dysenteriae type 1 toxin (Shiga toxin) $(12,19 ;$ A. D. O'Brien, T. A. Lively, T. W. Chang, and S. L. Gorbach, Letter, Lancet ii:573, 1983). A role for this cytotoxin has been proposed in the pathogenesis of HUS, and growing evidence shows that VT-producing strains of $E$. coli, other than O157:H7 strains, are associated with HUS (M. A. Karmali, M. Petric, C. Lim,

\footnotetext{
* Corresponding author.
}

P. C. Fleming, and B. T. Steele, Letter, Lancet ii:1299$1300,1983)$. We believe that the same may be true for hemorrhagic colitis.

To investigate this, we screened all $E$. coli isolates from sporadic cases of hemorrhagic colitis over the past 3 years and sent to the Centers for Disease Control, Atlanta, Ga., testing them for moderate or high levels of VT production. Strains selected on this basis were characterized by serotype, biotype, and antimicrobial susceptibility. Current screening procedures are based on negative or slow fermentation of sorbitol and the detection of $\mathrm{H} 7$ antigen (11); most strains of $E$. coli, other than 0157:H7 strains, are thereby excluded from further analysis.

\section{MATERIALS AND METHODS}

Bacterial strains. $E$. coli strains isolated from patients with hemorrhagic colitis and sent to the Centers for Disease Control during a 3-year period were screened for VT production. Twenty-three toxigenic isolates were found to be different from the typical $E$. coli $\mathrm{O} 157: \mathrm{H} 7$ strains and were included in this study of unusual VT-producing $E$. coli associated with hemorrhagic colitis. Biochemical and serological identification of these strains was performed as described previously $(4,6,8)$. Antimicrobial susceptibility to ampicillin, cephalothin, chloramphenicol, gentamicin, kanamycin, naladixic acid, neomycin, nitrofurantoin, sulfisoxazole, streptomycin, tetracycline, and trimethoprimsulfamethoxazole was determined by the disk diffusion method (1).

VT and adherence assays. Strains to be assayed for VT production were inoculated into Evans CAYE (2\% Casamino Acids, $0.15 \%$ yeast extract, $0.25 \% \mathrm{NaCl}, 0.871 \% \mathrm{~K}_{2} \mathrm{HPO}_{4}$, $0.25 \%$ glucose, $0.1 \%$ trace salts solution $\left[5 \% \mathrm{MgSO}_{4}, 0.5 \%\right.$ $\left.\mathrm{MnCl}_{2}, 0.5 \% \mathrm{FeCl}_{3} \cdot 6 \mathrm{H}_{2} \mathrm{O}\right], \mathrm{pH} 8.5$ ). The broth cultures were incubated for $24 \mathrm{~h}$ at $37^{\circ} \mathrm{C}$ on a roller drum rotating at $20 \mathrm{rpm}$. Broth cultures were centrifuged at $3,500 \times g$ for 20 min. The supernatants were removed and recentrifuged for 5 
TABLE 1. E. coli O157:H7 strains with unusual biochemical reactions or resistance to multiple antimicrobial agents

\begin{tabular}{lllllll}
\hline Strain & Origin & Yr & $\begin{array}{c}\text { VT } \\
\text { neutralization }\end{array}$ & $\begin{array}{c}\text { Antimicrobial } \\
\text { resistance }\end{array}$ & $\begin{array}{c}\text { Plasmid content } \\
\text { (MDa) }\end{array}$ & $\begin{array}{c}\text { Unusual biochemical } \\
\text { reactions }\end{array}$ \\
\hline $161-84$ & Ohio & 1982 & $\mathrm{P}$ & None & 60 & Citrate $(+)$ \\
$1011-84$ & Maine & 1984 & $\mathrm{P}$ & None & $60,2.1$ & Indole $(-)$ \\
$3230-85$ & Washington & 1985 & $\mathrm{P}$ & None & $60,2.1$ & Citrate $(+)$ \\
$3124-85$ & Massachusetts & 1985 & + & Tc Sm Su & $60,40,2.1$ & None \\
A9167-1 & Washington & 1983 & + & Tc Sm Su & $60,2.1$ & None \\
$3174-87$ & Texas & 1987 & - & None & 60,30 & Urea (+) \\
\hline
\end{tabular}

${ }^{a}$ Neutralization was determined by using a monoclonal antibody directed against Shiga-like toxin as described by Strockbine et al. (18). P, Partial neutralization.

${ }_{b}^{b}$ Tc, Tetracycline; Sm, streptomycin; Su, sulfisoxazole.

min. The resulting supernatants were assayed in Vero cells for the presence of cytotoxin as previously described (10). In some cases, the cells were collected by centrifugation, lysed by sonication, and assayed in Vero cells in the same manner as the supernatants were (12).

Toxin neutralization was determined with a monoclonal antibody to one VT1 (SLT-I). The antibody is described in detail elsewhere (18) and was kindly provided by N. A. Strockbine and A. D. O'Brien of the Uniformed Services University of the Health Sciences, Bethesda, Md. Polymyxin B sulfate extracts of heart infusion agar-grown cultures were diluted 1:10 in cell growth medium and antiserum and incubated for $1 \mathrm{~h}$ at $37^{\circ} \mathrm{C}$, and $0.1-\mathrm{ml}$ extracts were applied to HeLa cell monolayers in microtiter plates. After overnight incubation, the wells were examined microscopically for cell death. The extent of neutralization was recorded as complete (VT1), partial (VT1 plus putative VT2), or none (putative VT2). A specific antibody against VT2 was not available.

All strains were assayed for adherence to HeLa cells as described by Scaletsky et al. (15).

Plasmid analysis. Plasmid DNA was isolated from all strains by the method of Birnboim and Doly (2). Plasmid DNA preparations were electrophoresed through a vertical agarose gel at $35 \mathrm{~mA}$ for 2 to $2.5 \mathrm{~h}$. Gels were then stained with ethidium bromide, examined under UV light, and photographed. Plasmid sizes were estimated by comparison to plasmids of known molecular weight included on each gel. These control plasmids were R1 (62 megadaltons [MDa]), RP4 (36 MDa), S-a (23 MDa), and pDK9 (140 and $105 \mathrm{MDa})$.

\section{RESULTS}

More than 200 VT-producing $E$. coli isolates from hemorrhagic colitis gave reactions typical of $E$. coli, except for sorbitol fermentation. As described previously, $E$. coli 0157:H7 strains do not ferment sorbitol in less than $72 \mathrm{~h}(5$, 20). Of these $200 E$. coli $0157: \mathrm{H} 7$ strains, none were resistant to 12 antimicrobial agents when tested by the disk diffusion method. Twenty-three isolates were unusual and fell into three groups. The first group included six atypical $E$. coli $0157: \mathrm{H} 7$ strains. Two of these strains were resistant to three antimicrobial agents, one was indole negative, one was urea positive, and two were able to use citrate (Table 1). The second group consisted of six nonmotile 0157 strains (i.e., they lack the flagellar $\mathrm{H}$ antigen) (Table 2). These two groups of isolates were similar to typical $0157: \mathrm{H} 7$ strains by plasmid profile (all possess a $60-\mathrm{MDa}$ plasmid) and a negative or slow sorbitol fermentation reaction.

The third group of VT-producing $E$. coli did not belong to the $\mathrm{O} 157$ serogroup, and only one isolate had the flagellar $\mathrm{H} 7$ antigen $(\mathrm{O} 50: \mathrm{H} 7)$ (Table 3). Two isolates were recognized enteropathogenic $E$. coli (EPEC) serotypes, O111:NM and $\mathrm{O} 26: \mathrm{H} 11$, and one isolate belonged to EPEC serogroup $\mathrm{O} 111$ (serotype O111:H8). Although adherence to HeLa cell tissue culture is a frequent characteristic of EPEC strains (15), none of the isolates in this study adhered to HeLa cells. All isolates in the third group contained at least one large plasmid, ranging from 46 to $73 \mathrm{MDa}$, but the profiles were not similar, except possibly for the two 0111 serogroup strains. None of the plasmid profiles were similar to those of the typical O157:H7 strains.

Typical $E$. coli $0157: \mathrm{H} 7$ strains produced VTs that were wholly or partially capable of being neutralized with the monoclonal antibody to VT1. One of the 0157:H7 strains, one of the nonmotile 0157 strains, and three of the strains in group 3 appeared to produce VT which was not neutralized by the monoclonal antibody.

\section{DISCUSSION}

Strains of $E$. coli $0157: \mathrm{H} 7$ isolated from outbreaks and sporadic cases of hemorrhagic colitis and HUS have been found to have similar plasmid profiles, to be susceptible to antimicrobial agents, to be unable to ferment sorbitol within $48 \mathrm{~h}$, and to produce moderate to high levels of VT $(12,20$; Johnson et al., Letter). None of the $E$. coli 0157 strains with other $\mathrm{H}$ antigens, taken from the Centers for Disease Control culture collection, were isolated from persons with hemorrhagic colitis; they had diverse plasmid profiles, were able to ferment sorbitol rapidly, and did not produce detectable levels of VT. Until recently, O157:H7 strains have been considered to be a single clone which might be the only cause of hemorrhagic colitis. Investigators have used screening procedures based on $\mathrm{H} 7$ immobilization and sorbitol fermentation which would ignore other $E$. coli $(5,11)$.

By using a screening procedure for toxin production, we have identified several atypical 0157:H7 strains and nonmotile $\mathrm{O} 157$ serogroup strains during this 3-year study.

TABLE 2. Nonmotile $E$. coli $\mathrm{O} 157$ strains isolated from patients with hemorrhagic colitis

\begin{tabular}{llcccc}
\hline Strain & \multicolumn{1}{c}{ Origin } & Yr & $\begin{array}{c}\text { VT } \\
\text { neutrali- } \\
\text { zation }^{a}\end{array}$ & $\begin{array}{c}\text { Antimicrobial } \\
\text { resistance }\end{array}$ & $\begin{array}{c}\text { Plasmid } \\
\text { content } \\
\text { (MDa) }\end{array}$ \\
\hline $3123-85$ & North Dakota & 1985 & + & None & $60,2.1$ \\
$3199-85$ & Massachusetts & 1985 & - & None & 60,40 \\
$3205-85$ & Michigan & 1985 & $\mathrm{P}$ & None & $60,2.1$ \\
$3344-85$ & Maryland & 1985 & $\mathrm{P}$ & None & 60,40 \\
$3444-85$ & Massachusetts & 1985 & $\mathrm{P}$ & None & $60,2.1$ \\
$3460-85$ & Massachusetts & 1985 & $\mathrm{P}$ & None & $60,2.1$ \\
\hline
\end{tabular}

a Neutralization was determined by using a monoclonal antibody directed against Shiga-like toxin as described by Strockbine et al. (18). P, Partial neutralization. 
TABLE 3. Serotypes (other than $\mathrm{O} 157: \mathrm{H} 7$ or nonmotile 0157 ) of $E$. coli isolated from patients with hemorrhagic colitis

\begin{tabular}{|c|c|c|c|c|c|c|c|}
\hline Strain & Origin & $\mathrm{Yr}$ & Serotype & $\begin{array}{c}\text { VT } \\
\text { neutralization }^{a}\end{array}$ & Adherence & $\begin{array}{l}\text { Antimicrobial } \\
\text { resistance }^{b}\end{array}$ & Plasmid content (MDa) \\
\hline $75-83$ & South Dakota & 1982 & O145:NM & + & - & None & 67 \\
\hline A9619-C2 & Michigan & 1983 & $\mathrm{O} 45: \mathrm{H} 2$ & + & - & $\begin{array}{c}\mathrm{Cm} \mathrm{Tc} \mathrm{Na} \mathrm{Ap} \mathrm{Cb} \\
\mathrm{Km} \mathrm{Sm} \mathrm{Su}\end{array}$ & $60,26,15.3,9.1,4.9$ \\
\hline $3007-85$ & Nebraska & 1985 & O111:NM & $\mathbf{P}$ & - & None & $50,12.3,8.6$ \\
\hline $3143-85 b$ & United Kingdom & 1985 & O5:NM & + & - & $\mathrm{Sm} \mathrm{Su}$ & $54,26,7.5,3.7,3.2,2.6$ \\
\hline $3288-85$ & California & 1985 & Ound:NM & - & - & None & 46 \\
\hline $3377-85$ & Georgia & 1983 & O4:NM & $\mathbf{P}$ & - & Tc Sm & $73,46,29,22.5,14.5,5.2$ \\
\hline $3030 A-86$ & Idaho & 1986 & O111:H8 & $\mathbf{P}$ & - & None & $50,14.5,12.3,8.6$ \\
\hline $3047-86$ & Australia & 1986 & $\mathrm{O} 26: \mathrm{H} 11$ & + & - & None & $54,9.2,8.6$ \\
\hline $3056-86$ & Maryland & 1986 & $\mathrm{O} 50: \mathrm{H} 7$ & - & - & None & 73 \\
\hline $3153 \mathrm{~B}-86$ & North Carolina & 1986 & O125:NM & + & - & None & $54,7.5$ \\
\hline $3056-85$ & Oklahoma & 1985 & O121:H19 & - & - & None & 54 \\
\hline
\end{tabular}

${ }^{a}$ Neutralization was determined by using a monoclonal antibody directed against Shiga-like toxin as described by Strockbine et al. (18). P, Partial neutralization.

${ }^{b}$ Sm, Streptomycin; Su, sulfisoxazole; Cm, chloramphenicol; Tc, tetracycline; Na, nalidixic acid; Ap, ampicillin; Cb, carbenicillin; Km, kanamycin.

Except for single biochemical reactions, antimicrobial resistance, and the lack of $\mathrm{H} 7$ antigen expression, these organisms are indistinguishable from the $\mathrm{H} 7$ clone; i.e., they have similar plasmid profiles, are slow in fermenting sorbitol, produce VT, and have been isolated from persons with hemorrhagic colitis. The nonmotile strains would not have been detected by one of the currently available screening procedures (5). Similarly, initial biochemical screening procedures would not usually recognize indole-negative, citratepositive, or urea-positive bacterial strains as $E$. coli and might eliminate those from further study. Apparently no single plasmid is associated with any atypical characteristic or antibiotic resistance in these strains, but more detailed genetic studies will be necessary to address this.

The VT-producing serotypes, other than $0157: \mathrm{H} 7$ or O157:NM, appear to constitute a diverse group (Table 3 ) and do not share other $\mathrm{H} 7$ clone characteristics. It is not surprising to find $E$. coli strains, other than $0157: \mathrm{H} 7$ strains, producing toxins that are generally bacteriophage mediated (19). In fact, at least two VT-producing phage have been identified within $\mathrm{O} 157: \mathrm{H} 7$ (19), and at least two antigenically distinct VTs have been detected within O157:H7 strains (18; Scotland et al., Letter). The monoclonal antibody used in this study neutralizes Shiga toxin and antigenically similar Shigalike toxin (SLT-I or VT1). It appears that the O, H, and toxin antigen diversity seen in HUS E. coli isolates (9) can also occur in hemorrhagic colitis $E$. coli isolates.

Only two of the serotypes in Table 3 have been recognized as enteric pathogens in the past. Serotypes O111:NM and O26: $\mathrm{H} 11$ are both classic EPEC strains and as early as 1977, were reported to produce VT (10). When investigators have selected $\mathrm{O} 111$ and $\mathrm{O} 26$ strains from culture collections, however, not all have produced detectable quantities of VT; therefore, this quality does not seem to be a universal characteristic of these $E$. coli serogroups $(3,16)$.

Production of VT by these unusual $E$. coli isolated from hemorrhagic colitis and HUS patients does not prove that these strains cause disease. However, the production of detectable amounts of VT in culture supernatants does seem to be at least a marker for $E$. coli strains associated with the illnesses, since moderate to high VT levels are rarely produced by $E$. coli associated with other types of diarrhea or from people who are not ill (12). Preliminary data also show that the VT-producing $E$. coli in Table 3 can cause a syndrome similar to that produced by $E$. coli $\mathrm{O} 157: \mathrm{H} 7$ in the gnotobiotic piglet; this syndrome is distinguishable from the one reported for EPEC infections (S. Tzipori, I. K. Wach- smuth, J. Smithers, and C. Jackson, submitted for publication). These organisms may well constitute a new group of pathogenic $E$. coli and should be useful in studies of pathogenesis.

Our findings also suggest that investigators using the various sorbitol and $\mathrm{H} 7$ screening media $(5,11)$ should use caution in interpreting or generalizing from their data. Prospective studies using VT screening, as well as current methods, are needed to determine the frequency with which VT-producing $E$. coli strains, other than 0157:H7 strains, are associated with disease.

\section{ACKNOWLEDGMENTS}

We thank Alison O'Brien, Nancy Strockbine, and Lillian R. M. Marques of the Uniformed Services University of the Health Sciences, Bethesda, Md., for help in establishing the HeLa cell assay for Shiga-like toxins, for providing the monoclonal antibody against SLT-I, and for confirmation of initial neutralization data. We also thank Patricia Newman for excellent secretarial support in preparing this manuscript.

\section{LITERATURE CITED}

1. Barry, A. L., and C. Thornsberry. 1985. Susceptibility tests: diffusion test procedures, p. 978-987. In E. H. Lennette, A. Balows, W. J. Hausler, Jr., and H. J. Shadomy (ed.), Manual of clinical microbiology, 4th ed. American Society for Microbiology, Washington, D.C.

2. Birnboim, H. C., and J. Doly. 1979. A rapid alkaline extraction procedure for screening recombinant plasmid DNA. Nucleic Acids Res. 7:1513-1523.

3. Cleary, T. G., J. J. Mathewson, E. Faris, and L. K. Pickering. 1985. Shiga-like cytotoxin production by enteropathogenic Escherichia coli serogroups. Infect. Immun. 47:335-337.

4. Edwards, P. R., and W. H. Ewing. 1972. Identification of Enterobacteriaceae, 3rd ed. Burgess Publishing Co., Minneapolis.

5. Farmer, J. J., III, and B. R. Davis. 1985. H7 antiserum-sorbitol fermentation medium: a single tube screening medium for detecting Escherichia coli $\mathrm{O} 157: \mathrm{H} 7$ associated with hemorrhagic colitis. J. Clin. Microbiol. 22:620-625.

6. Farmer, J. J., III, B. R. Davis, F. W. Hickman-Brenner, A. McWhorter, G. P. Huntley-Carter, M. A. Asbury, C. Riddle, H. G. Wathen-Grady, C. Elias, G. R. Fanning, A. G. Steigerwalt, C. M. O'Hara, G. K. Morris, P. B. Smith, and D. J. Brenner. 1985. Biochemical identification of new species and biogroups of Enterobacteriaceae isolated from clinical specimens. J. Clin. Microbiol. 21:46-76.

7. Gransden, W. R., S. Damm, J. D. Anderson, J. E. Carter, and H. Lior. 1986. Further evidence associating hemolytic uremic syndrome with infection by verotoxin-producing Escherichia 
coli 0157:H7. J. Infect. Dis. 154:522-524.

8. Hickman, F. W., and J. J. Farmer III. 1978. Salmonella typhi: identification, antibiograms, serology, and bacteriophage typing. Am. J. Med. Technol. 44:1149-1159.

9. Karmali, M. A., B. T. Steele, M. Petric, and C. Lim. 1983. Sporadic cases of hemolytic-uremic syndrome associated with faecal cytotoxin and cytotoxin-producing Escherichia coli in stools. Lancet i:619-620.

10. Konowalchuk, J., J. I. Speirs, and S. Stavric. 1977. Vero response to a cytotoxin of Escherichia coli. Infect. Immun. 18: 775-779.

11. March, S. B., and S. Ratnam. 1986. Sorbitol-MacConkey medium for detection of Escherichia coli $0157: \mathrm{H7}$ associated with hemorrhagic colitis. J. Clin. Microbiol. 23:869-872.

12. Marques, L. R. M., M. A. Moore, J. G. Wells, I. K. Wachsmuth, and A. D. O'Brien. 1986. Production of Shiga-like toxin by Escherichia coli. J. Infect. Dis. 154:338-341.

13. Remis, R. S., K. L. MacDonald, L. W. Riley, N. D. Puhr, J. G. Wells, B. R. Davis, P. A. Blake, and M. L. Cohen. 1984. Sporadic cases of hemorrhagic colitis associated with Escherichia coli 0157:H7. Ann. Intern. Med. 101:624-626.

14. Riley, L. W., R. S. Remis, S. D. Helgerson, H. B. McGee, J. G. Wells, B. R. Davis, R. J. Herbert, E. S. Olcott, L. M. Johnson, N. T. Hargrett, P. A. Blake, and M. L. Cohen. 1983. Hemorrhagic colitis associated with a rare Escherichia coli serotype.
N. Engl. J. Med. 308:681-685.

15. Scaletsky, I. C. A., M. L. M. Silva, and L. R. Trabulsi. 1984. Distinctive patterns of adherence of enteropathogenic Escherichia coli to HeLa cells. Infect. Immun. 45:534-536.

16. Scotland, S. M., N. P. Day, and B. Rowe. 1980. Production of a cytotoxin affecting Vero cells by strains of Escherichia coli belonging to traditional enteropathogenic serogroups. FEMS Microbiol. Lett. 7:15-17.

17. Spika, J. S., J. E. Parsons, D. Nordenberg, J. G. Wells, R. A. Gunn, and P. A. Blake. 1986. Hemolytic uremic syndrome and diarrhea associated with Escherichia coli $0157:$ H7 in a day care center. J. Pediatr. 109:287-291.

18. Strockbine, N. A., L. R. M. Marques, R. K. Holmes, and A. D. O'Brien. 1985. Characterization of monoclonal antibodies against Shiga-like toxin from Escherichia coli. Infect. Immun. 50:695-700.

19. Strockbine, N. A., L. R. M. Marques, J. W. Newland, H. W. Smith, R. K. Holmes, and A. D. O'Brien. 1986. Two toxinconverting phages from Escherichia coli $0157: \mathrm{H7}$ strain 933 encode antigenically distinct toxins with similar bịologic activities. Infect. Immun. 53:135-140.

20. Wells, J. G., B. R. Davis, I. K. Wachsmuth, L. W. Riley, R. S. Remis, R. Sokolow, and G. K. Morris. 1983. Laboratory investigation of hemorrhagic colitis outbreaks associated with a rare Escherichia coli serotype. J. Clin. Microbiol. 18:512-520. 